Art gilt und die Summationstöne des Harmoniums und der Doppelsirene, wie schon erwähnt, nachweislich objectiv, diejenigen aller übrigen Instrumente aber subjectiv sind, so ergibt sich, dass zwischen objectiven und subjectiven Summationstönen ebensowenig ein principieller Unterschied besteht wie zwischen den subjectiven und objectiven Differenztönen. So bestätigt also die experimentelle Beobachtung auch in dieser Richtung vollkommen die soeben hinsiehtlich des Ursprungs der Combinationstöne theoretisch abgeleitete Analogie $z$ wischen dem Harmonium und dem inneren Ohre.

\title{
Berichtigung von
}

E. Pflüger.

In meiner Abhandlung (Bd. 77, S. 465) ist nicht 3,4 als calorischer Coëfficient des Sauerstoffs für Stärke zu lesen, sondern 3,53. 